\title{
Are Mastery-Oriented College Students Better Time Managers?
}

\author{
Miriam Romero $^{1} \mathbb{D} \cdot$ James F. Juola $^{2}$ (D) Cristina Casadevante ${ }^{1}$ D . \\ José Manuel Hernández ${ }^{1}$ (D) . José Santacreu ${ }^{1}$ (D)
}

Accepted: 27 July 2021 / Published online: 18 August 2021

(c) The Author(s) 2021

\begin{abstract}
Goal orientation and time management have been major components of most selfregulated learning models. They are also especially relevant for adaptative outcomes in the field of education. Goal orientation and time management have traditionally been measured through self-reports, and, although few studies have explored both variables, a positive and significant relation between them has been reported. However, it has been questioned whether people can provide accurate information about their own behavior. Therefore, there is a need for new and less subjective measures to assess these variables. In the present work, we administered objective tests to study goal orientation and time management to expand upon previous findings. Results indicated that goal orientation and time management measured objectively show a positive and significant relation. Mastery-oriented students manage their time more efficiently. Performance-oriented students tend to complete activities with lower values and initiate more task interruptions, resulting in less efficient time management.
\end{abstract}

Keywords Objective test · Goal orientation · Time management $\cdot$ Self-regulation

Miriam Romero

miriam.romero@uam.es

James F. Juola

juolas@ku.edu

Cristina Casadevante

cristina.casadevante@uam.es

José Manuel Hernández

josemanuel.hernandez@uam.es

José Santacreu

jose.santacreu@uam.es

1 Department of Psychology, Universidad Autónoma de Madrid, C/Iván Pavlov, nº 6. 28049, Madrid, Spain

2 Department of Psychology, Department of Psychology, University of Kansas, 1415 Jayhawk Blvd., Fraser Hall, Room 426, Lawrence, KS 66045-7556, USA 
Goal orientation (mastery and performance orientations) and time management are relevant variables of self-regulated learning theory, which describes proactive variables that promote learning. Researchers who have developed influential self-regulated learning models are Zimmerman (2000, 2013) and Pintrich (2000; see Panadero, 2017, for a review). These authors argue that, when people face tasks, they are often proactive agents in the process. They establish goals, prepare for action, execute it, and then make adjustments based on the results of their own performance. Several variables are involved in the self-regulation process, and, among them, the authors point out that goal orientation and time management have a great relevance for the achievement of goals (e.g., Pintrich, 2000; Zimmerman, 2008).

Goal orientation theory describes two main approaches that people use to establish and pursue a goal (see Ames, 1992; Dweck \& Leggett, 1988). These approaches are named mastery- and performance-orientation. Mastery-oriented people are interested in learning how to improve their competence. They consider new or difficult tasks as challenges and they show effort and positive emotions when facing them. Performance-oriented people, on the other hand, want to achieve gains and the best results, regardless of whether it implies learning or not. When facing new tasks, they want to demonstrate their competence, but if the tasks are difficult, they tend to experience negative emotions (e.g., Ames, 1992; Dweck \& Leggett, 1988; Elliot, 2005; Morrone \& Schutz, 2000; Payne et al., 2007). Mastery-orientation has been related to positive outcomes, such as higher levels of learning, persistence, and academic engagement. Thus, it has been recommended that educators encourage this type of orientation in the classroom (e.g., Ames, 1992; Digelidis et al., 2003; Gonida et al., 2009; Leondari \& Gialamas, 2002; Sosik et al., 2017).

Time management refers to behaviors that are directed to employ time efficiently when a goal has been established (Claessens et al., 2007, pp. 262-263) and as selfcontrolled attempts to employ time efficiently to achieve one's goal (Koch \& Kleinmann, 2002, p. 201). Behavioral decision-making theory is one of the most important theories in the time management literature (Koch \& Kleinmann, 2002; Sevary \& Kandy, 2011). According to the theory, successful time managers consider the costs and benefits of the different activities that need to be done and choose the order in which to complete them so that they efficiently achieve their goals. They tend to consider long-term benefits and not only immediate gains. Alternatively, people who do not manage their time well often initiate tasks without considering an optimal order in which to complete them. In addition, they are more likely to interrupt activities that they have started before the task is completed (König \& Kleinmann, 2006, 2007). Time management is considered to be a learned strategy (Zimmerman, 1996), and better time management has been related to positive outcomes, such as higher levels of engagement in educational activities and better academic performance (Britton \& Tesser, 1991; Claessens, 2004; Claessens et al., 2007; Macan et al., 1990; Petersen et al., 2016; Thibodeaux et al., 2017). Given its relevance to academic performance, time management training programs has been emphasized in the educational field (e.g., Ahmad-Uzir et al., 2019; Thibodeaux et al., 2017).

Goal orientation and time management have been traditionally measured using self-reports. Regarding goal orientation, the most commonly employed self-reports are the General Learning and Performance Orientation Scale (Button et al., 1996), 
the Patterns of Adaptative Learning Scale (Midgley et al., 2000), and the Achievement Goal Questionnaire-Revised (Elliot \& Murayama, 2008). When it comes to measuring time management, the most commonly employed self-reports are the Time Management Behavior Questionnaire (TMBQ; Macan et al., 1990) and the Time Management Questionnaire (TMQ; Britton \& Tesser, 1991). These instruments collect information based on people's verbal descriptions of their behavior and are easy to administer and score. However, several authors have stressed the limitations of self-reports (e.g., Pike, 1995; Santacreu et al., 2006). It has been questioned whether people can accurately self-evaluate and describe what they are being asked about in such questionnaires, as the descriptions people provide about their behavior are not always accurate (Núñez et al., 2006; Santacreu \& Hernández, 2017; Scheier, 1958). Besides, people's responses can be affected by biases such as social desirability effects (Edwards, 1957). Some studies of self-regulated learning show that, when people self-report their behavior, they tend to claim that they employ strategies more frequently than they actually do when their behavior is observed and registered directly (Bernacki et al., 2012; Winne \& Jamieson-Noel, 2002; Zimmerman, 2008). These criticisms have led to a call for new approaches and objective methods to assess goal orientation, time management, and other variables that have been studied from the perspective of self-regulated learning models (see Panadero, 2017).

In efforts to provide more objective measures of goal orientation and time management, researchers have employed instruments such as software that collects behavior online or objective computerized tests. Software that records student actions while studying course materials, for example, includes gStudy (Winne et al., 2006) to assess goal orientation and PrepMate (Chu et al., 1998) to study time management. The $g S t u d y$ software records the labels assigned by participants to material they have to study. The labels reflect aspects of the studied material that they have to learn or have to consider later in order to obtain a high score in an exam. PrepMate records how participants process the text to be studied (pre-review, underlining, annotations, etc.). These instruments serve as complements to self-reports, but administration times are usually long (around 30-50 min per test). Objective computerized tests present situations in which people have to perform tasks, instead of requiring people to describe their behavior. They are called objective tests because of their double objectivity: like self-reports, objective tests are objective from the point of view of the assessor, as two different researchers should observe the same scores. However, objective tests are also objective from the point of view of the person being assessed, as their behaviors are more difficult to disguise. The responses are observable without personal or subjective interpretations (Cattell, 1958; Cattell \& Warburton, 1967; Ortner \& Proyer, 2015; Santacreu \& Hernández, 2017; Scheier, 1958). The administration times of the objective tests are usually short (7-15 min per test). This methodology has the potential to become a useful instrument and provide complementary information about variables that have traditionally been measured through self-reports. In the present work, we will measure goal orientation and time management by using objective tests, which will be described later.

From self-regulated learning models (e.g., Pintrich, 2000; Zimmerman, 2000, 2013), it has been demonstrated that students who are better self-regulators tend to 
show a mastery orientation. They generally make a deliberate effort to learn in the process of completing tasks. Also, mastery-oriented students try to manage their time to achieve their aims, which usually leads to higher efficiency in completing the tasks. Nevertheless, although goal orientation and time management are important components of self-regulated learning models, few studies have explored both variables concurrently. The studies that have considered both have measured them by using self-reports. Results show that mastery-orientation is positively related to time management (with correlation values between 0.20 and 0.48; e.g., Luo et al., 2011; Magno, 2012; Ranellucci et al., 2015; Won et al., 2018). However, as we have indicated, the information provided by students through self-reports may not be accurate.

In order to expand on previous findings, we have conducted a study to determine how mastery- and performance-oriented students manage their time. We will describe goal orientation and time management from a behavioral approach, measuring them by using objective tests. The study will allow determination of whether the empirical results are in line with the theoretical descriptions derived from selfregulated learning and goal orientation theories. Ultimately, this work is intended to establish a precedent for future studies in which objective measures are employed.

The Mastery Performance-Goal Orientation Test (MP-GOT; Romero et al., 2020) will be employed to assess goal orientation. This test measures goal orientation along a single bipolar dimension. It presents a matrix with different figures that, when clicked on, reward the participant with various numbers of points. One category of figures (optimal figures) provides higher numbers of points than the other figures. Participants can obtain points by restricting their clicks to the category of figures that provide the highest number of points (mastery-oriented participants) or by clicking on as many figures as possible (performance-oriented participants).

We will also employ an objective test to study time management: the My Schedule objective test (Romero et al., 2021). My Schedule has been designed to assess time management in adults and presents tasks related to office and academic contexts. In this test, a schedule page with activities and hours of the day is presented. The activities (writing emails, working on a computer, answering calls, attending a meeting, and downloading documents) are represented by different icons. As will be described in the "Method" section, completing each activity provides a different number of points and takes different amounts of time to complete. Therefore, they have different values (the value of the activity is based on the points it provides divided by the seconds it lasts until it is completed). In addition, the schedule page presents some highlighted hours. If an activity is completed in a highlighted hour, twice the number of points is awarded. There is one activity that can be completed at the same time as others: "downloading documents." Also, if participants click on the "answering calls" activity when another activity is being completed, the activity being completed is interrupted. Participants have to make optimal decisions to obtain a higher number of points; that is, they have to click on the activities with higher values so that they can be completed during highlighted hours. Moreover, they should avoid interrupting other activities.

As described before, it is theorized that mastery-oriented students should tend to manage their time to achieve their goals by employing learning strategies. They 
are interested in learning and thereby improving their competences. Therefore, we expect mastery-oriented people to show better time management behaviors than performance-oriented people. According to behavioral decision-making theory, people with better time-management skills should try to complete higher-valued activities in any given time while avoiding task interruptions. As My Schedule allows us to determine whether high-value activities are being completed and whether other activities are being interrupted, we expect that mastery-oriented participants will be more likely to complete activities that offer higher rewards while avoiding interruptions more effectively than performance-oriented participants.

\section{Method}

\section{Participants}

We conducted an a priori analysis using $G^{*}$ Power (see Faul et al., 2009) to determine the minimum sample size needed based on the previous works that have studied the relation between goal orientation and time management (values between 0.20 and 0.48; Luo et al., 2011; Magno, 2012; Ranellucci et al., 2015; Won et al., 2018). The analysis showed that, establishing an alpha level of 0.05 and a desired power of 0.95 , the minimum sample size should be about 45 participants.

The total number of participants was 113 (10 males and 103 females). Participants were students in the first year of study of a psychology degree. Their average age was 20 years (the range was from 18 to 25). As a reward for their participation, they obtained course credits.

\section{Instruments}

\section{Goal Orientation}

Mastery Performance-Goal Orientation Test MP-GOT (Romero et al., 2020) assesses performance- and mastery-orientation along a single bipolar dimension. It presents a $15 \times 15$ matrix (225 squares) within which 150 figures are randomly distributed. The figures represent animals, plants, vehicles, and fruits (see Fig. 1). When clicking on the figures, participants obtain points. A specific category of figures (non-mammal animals) provides the highest number of points, while other categories (e.g., mammals animals, cars) provide 3, 1, or 0 points. The test records the figures clicked and the points obtained. It is possible to obtain a high number of points by restricting the clicks to the non-mammal animals' category (optimal figures) or by clicking on as many figures as possible. The participants who follow the first strategy are classified as mastery-oriented, and those who follow the second strategy are classified as performance-oriented. MP-GOT has 6 training trials and 6 test trials that last $20 \mathrm{~s}$ each. 


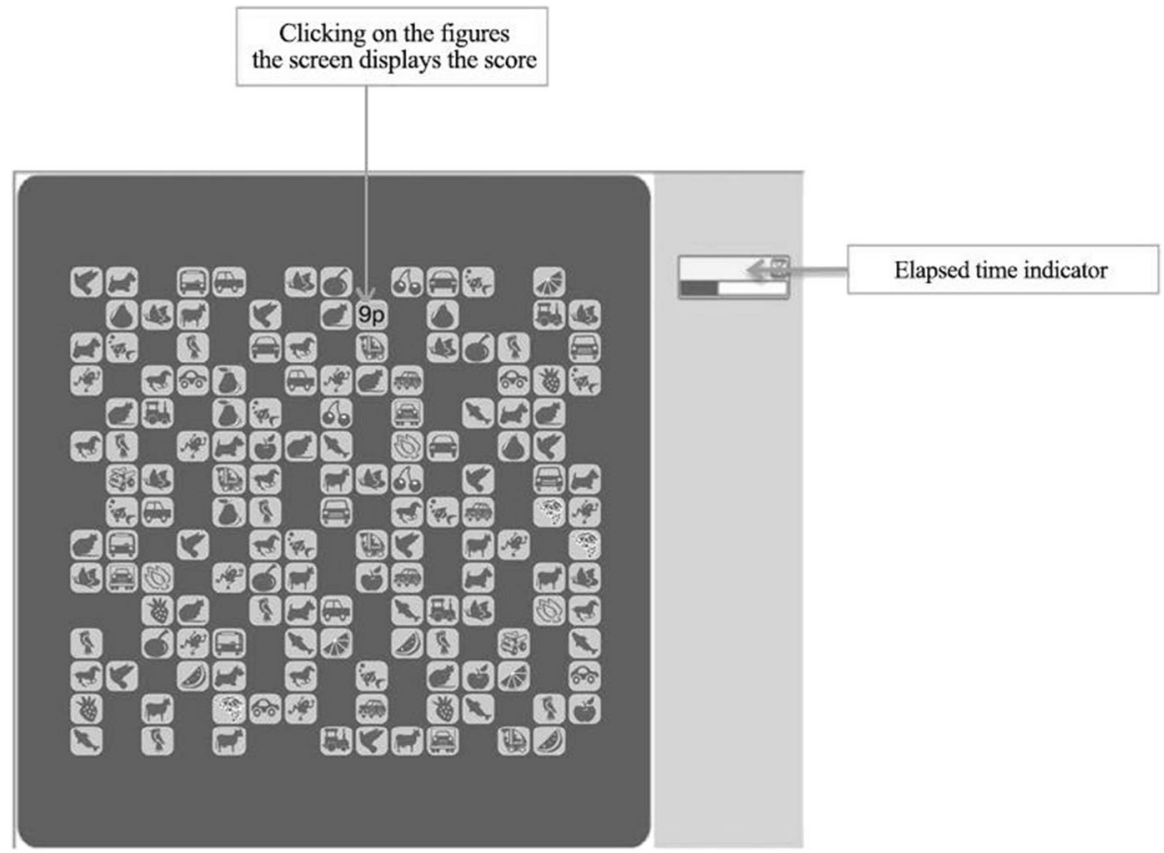

Fig. 1 Example of a display shown on each trial of the MP-GOT test (Romero et al., 2020)

The goal orientation variable was calculated as follows: mean number of ((total points over the last six trials)/(total responses in the last six trials)). Its observed value varied between 2.6 and 6.7. Obtaining low values usually results from ignoring the differences in points among figure categories. Obtaining high values usually results from restricting clicks to the category of figures that provide the highest number of points. Participants with lower scores were classified as performance-oriented (as they tended to obtain a higher number of points regardless of the learning level they achieved), and participants who obtained higher scores were classified as mastery-oriented (as they were those who tried to understand the requirements of the task and learned how to do so during the process). Romero et al. (2020) previously reported that MP-GOT showed high reliability (Cronbach's alpha was $0.97-0.98)$ and that predicted the scores of a learning task $\left(R^{2}=0.56\right)$. In the present study, Cronbach's alpha was 0.96 .

\section{Time Management}

My Schedule This test was developed by Romero et al. (2021). Its design was based on behavioral decision-making theory (Koch \& Kleinmann, 2002), one of the theories that has gained substantial empirical support in recent years in the time management literature. The test presents a schedule page that shows hours during a day (see Fig. 2) and activities to complete (writing emails, answering calls, working on the computer, attending a meeting, and downloading documents). The activities of $M y$ 


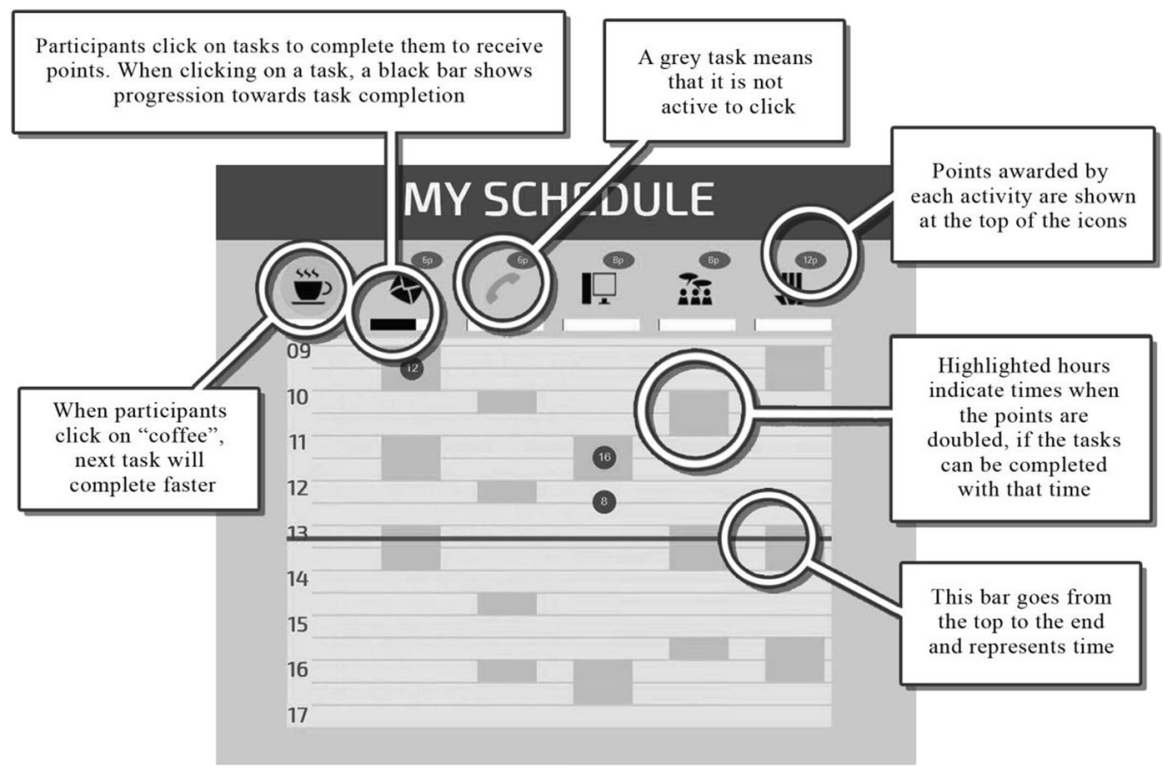

Fig. 2 Example of a display shown on each trial of My Schedule test (Romero et al., 2021)

Schedule represent tasks for which the test and target population was designed (daily activities for office workers and university students). A bar moving from the top to the end of the schedule page was used to represent time of day passing.

The activities provide different numbers of points and take different amounts of time to complete (see Table 1). The schedule page presents highlighted hours. If the activities are completed in the highlighted hours, they provide twice as many

Table 1 Points awarded by activities of My Schedule

\begin{tabular}{|c|c|c|c|c|}
\hline & Time it consumes & $\begin{array}{l}\text { Points awarded } \\
\text { if completed }\end{array}$ & $\begin{array}{l}\text { Value } \\
\text { (points/ } \\
\text { time) }\end{array}$ & $\begin{array}{l}\text { Value if completed } \\
\text { on highlighted } \\
\text { hours }\end{array}$ \\
\hline Writing emails & 4 & 6 & 1.5 & 3 \\
\hline Answering calls ${ }^{a}$ & 2 & 6 & 3 & 6 \\
\hline Working on the computer & 4 & 8 & 2 & 4 \\
\hline Attending a meeting & 4 & 8 & 2 & 4 \\
\hline Downloading documents $\mathrm{b}$ & $1-12$ & 12 & $12-1$ & $24-2$ \\
\hline Coffee (break) ${ }^{\mathrm{c}}$ & 5 & - & - & - \\
\hline
\end{tabular}

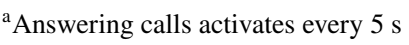

${ }^{b}$ Downloading documents is available even if another task is being completed. It consumes $1 \mathrm{~s}$ if the participant immediately clicks on another activity or up to $12 \mathrm{~s}$ if he or she clicks on another activity when "downloading documents" ends

${ }^{\mathrm{c}}$ The function of this activity is to halve the time that consumes the next activity that participants click 
points. When an activity is completed, a circle is placed on the schedule page showing the number of points awarded.

The activity named "downloading documents" can be completed at the same time as other activities. The "answering calls" activity activates every $5 \mathrm{~s}$, and if the participant clicks on it at the same time as another activity is being completed, the other activity is interrupted and therefore does not provide the points that could have been awarded. The schedule page also shows a button that represents having a break (coffee icon; see Fig. 2). When clicked, the next activity on which the participant clicks will take half the time to complete.

My Schedule has one training trial that lasts $120 \mathrm{~s}$ and eight test trials that last $60 \mathrm{~s}$ each. Before the first trial, instructions were presented. In the training trial, the moving bar moved down from the top to the bottom of the schedule page. In test trials, the moving bar moved down until 2PM, representing that the work hours finished at that time. Participants were told to ignore the last hours of the schedule page. The total duration of all trials was about $10 \mathrm{~min}$.

My schedule provides information on the total number of activities completed, the number of activities completed in the highlighted hours, and the total number of activities interrupted. The time management variable is measured by the mean number of points obtained in the test trials. Romero et al. (2021) reported that the reliability of My Schedule was high (Cronbach's alpha $=0.92-0.94$; test-retest (1 month) $r=0.71)$ and provided evidence of convergence validity $(r=0.31)$ with another test that measures time management behaviors (Planning test; Santacreu, 2004). In this work, the reliability (Cronbach's alpha) of the time management variable measured by My Schedule was 0.92 .

\section{Procedure}

The study was approved by the research ethics committee. First, the minimum sample size was determined. Then, the participants were recruited. All participants signed an informant consent document indicating that they would allow their anonymous data to be employed in the study. They were provided a secure user ID and a password. After that, they completed the computerized tests on individual computers. Two psychologists supervised the test administration.

\section{Data analysis}

As stated before, we first conducted an a priori analysis using G*Power (Faul et al., 2009) to determine the minimum sample size needed. The version employed was 3.1.9.4. Once collected, data analysis was performed using SPSS 26. We obtained descriptive statistics and calculated mean differences $(t$-test for independent samples). 


\section{Results}

The first analysis checked the relation between goal orientation (MP-GOT) and time management (My Schedule) in the entire sample $(n=113)$. Goal orientation $(M=4.27$; $\mathrm{SD}=1.29)$ and time management $(\mathrm{M}=164.1$; $\mathrm{SD}=32.7)$ showed a significant positive relation $(r=0.26 ; p<0.05)$, although the strength of the relationship was relatively small. In order to study mastery- and performance-oriented groups, we divided the sample using Romero et al. (2020) criterion, in which we observed that the value of 4.4 (which represents the mean value of the goal orientation measure in a previous large sample) allows an adequate division between mastery- and performance-oriented participants. We chose the established criterion to maintain consistency with the studies of Romero et al. (2020). People with a goal orientation score above 4.4 were classified as mastery-oriented, whereas those with a goal orientation score below 4.4 were classified as performance-oriented. In our study, 61 students were classified as performanceoriented and 52 students were classified as mastery-oriented.

To check the hypothesis regarding differences between mastery- and performanceparticipants, we calculated mean differences in the variables provided by My Schedule ( $t$-test for independent samples; see Table 2). Mastery-oriented participants obtained higher scores in the time management variable. In addition, the mean number of activities completed was significantly higher for the mastery-oriented group, and the same was true for the mean number of activities completed in the highlighted hours. The effect size (see Cohen, 1988) was medium for time management $\left(\eta^{2}=0.09\right)$ and the mean of the total number of activities completed $\left(\eta^{2}=0.06\right)$. The effect size was large for the mean number of activities completed in highlighted hours $\left(\eta^{2}=0.17\right)$. Finally, the mean number of activities interrupted was significantly higher for the performanceoriented group, with a medium effect size $\left(\eta^{2}=0.12\right)$.

We found no significant differences between the mastery- and performance-groups regarding the mean number of specific activities completed ("writing emails," "answering calls," "working on the computer," "attending a meeting," and "downloading documents"; see Table 3). However, there were significant differences regarding the mean number of specific activities completed in the highlighted hours. The mastery-oriented group completed more activities labeled as "answering calls," "working on the computer," "attending a meeting," and "downloading documents" in the highlighted hours. There were no significant differences regarding the mean number of "writing emails" activities completed in the highlighted hours. The effect sizes were medium for "downloading documents (highlighted hours)" $\left(\eta^{2}=0.11\right)$ and low for "answering calls (highlighted hours)" ( $\left.\eta^{2}=0.05\right)$, "working on the computer (highlighted hours)" $\left(\eta^{2}=0.05\right)$, and "attending a meeting (highlighted hours)" $\left(\eta^{2}=0.06\right)$.

\section{Discussion}

Goal orientation and time management play a role in the most frequently cited self-regulated learning models (Pintrich, 2000; Zimmerman, 2000, 2013; see Panadero, 2017). Self-reports have been the most widely used instruments to assess goal 


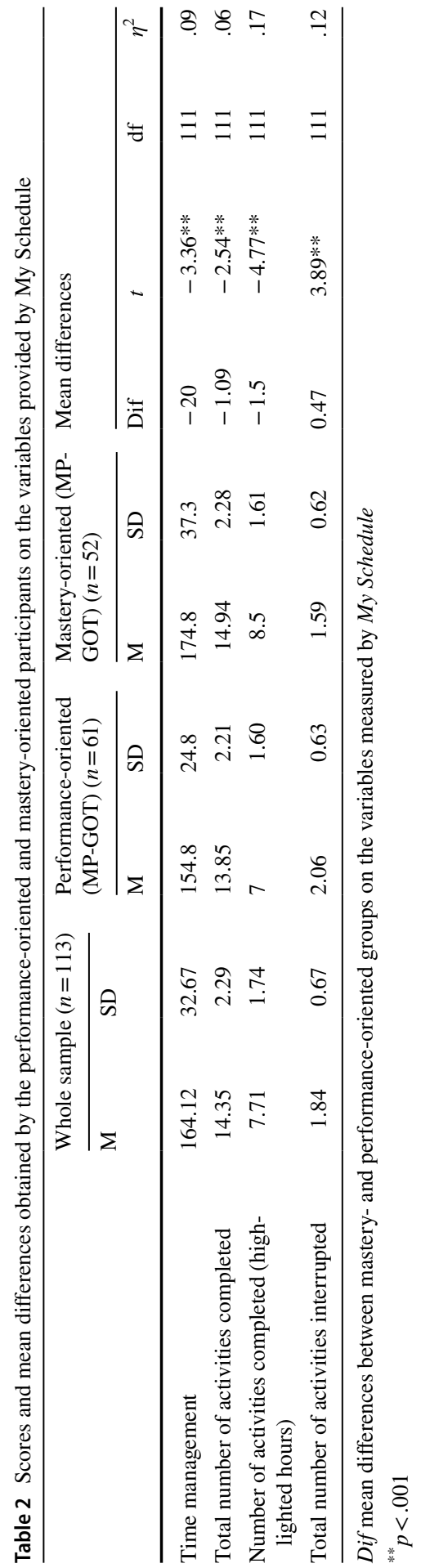




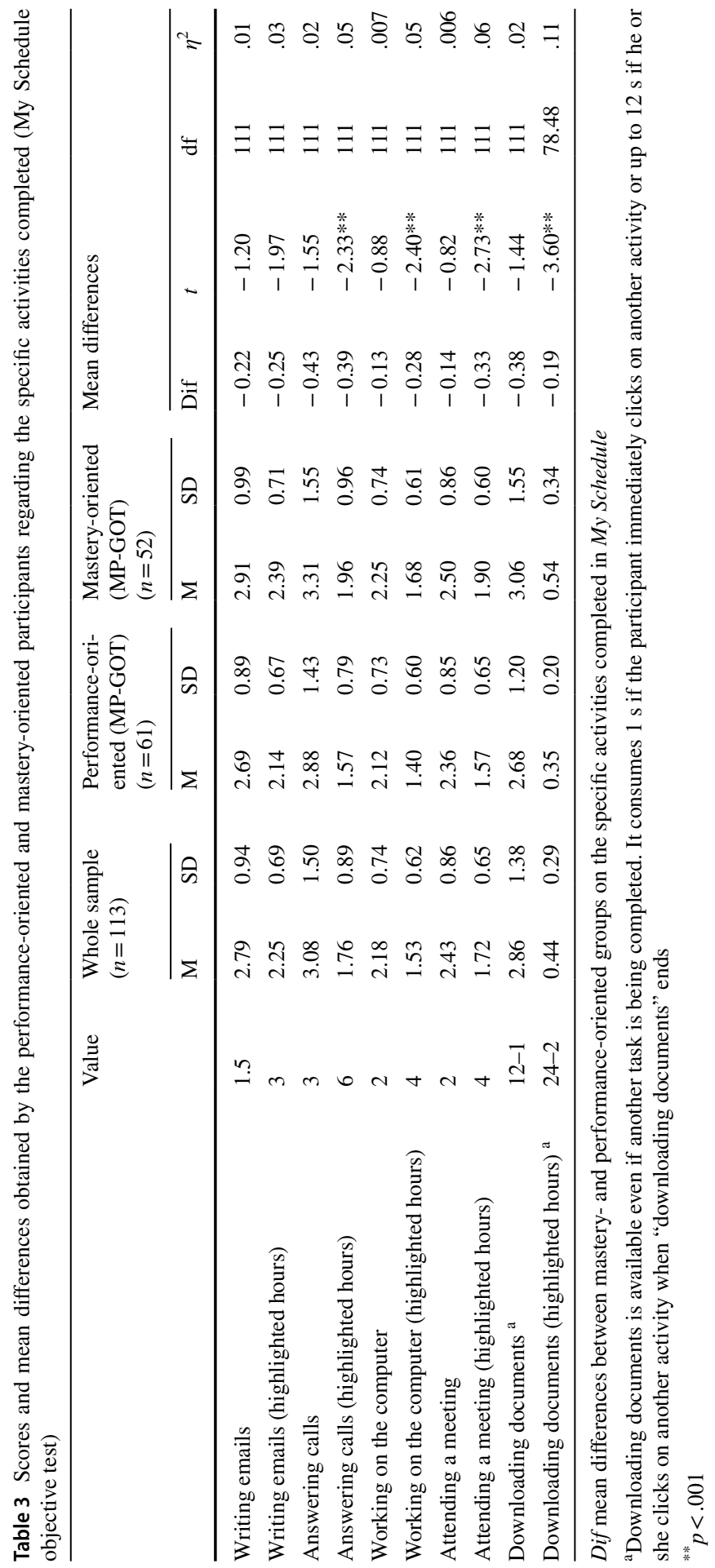


orientation and time management. However, self-reports suffer from limitations, and the need for new approaches and objective instruments has been emphasized (see Panadero, 2017). In the present work, we studied goal orientation and time management from a behavioral approach and employed objective tests to measure both variables objectively.

The relation between goal orientation and time management as objectively measured in the present study was positive and significant $(r=0.26)$. The correlation is not highly impressive, but it is consistent with previous research in which selfreports have been employed (Luo et al., 2011; Magno, 2012; Ranellucci et al., 2015; Won et al., 2018 found values between 0.20 and 0.48). Both studies that administered self-reports and the present study in which objective tests were employed show results that are in line with theoretical approaches regarding goal orientation and time management. From self-regulated learning and goal orientation theories, it is expected that mastery-oriented students manage their time better than performanceoriented students. Objective and subjective measures show that both variables are positively related, although the relation does not seem to be very strong.

The present work complements the correlational analyses of previous studies with the analysis of mean differences regarding mastery-and performance-oriented students in specific time management components. In the time management objective test (My Schedule), mastery-oriented students employed their time more efficiently. They managed to complete more activities in total. Furthermore, they managed to complete more activities in the highlighted hours (the hours that provide twice as many points) than did the performance-oriented participants. We found no significant differences in one of the activities (writing emails) completed in the highlighted hours. However, "writing emails" is the least-valued activity (see Table 1). Therefore, it seems that mastery-oriented students focused mainly on completing the more valuable activities in the highlighted hours, which suggests that they were managing their time more efficiently. Finally, performance-oriented students interrupted more activities than their mastery-oriented peers, which prevented performance-oriented students from obtaining higher scores. Performance-oriented participants did not seem to be focusing on choosing the activities that offered higher values, and they interrupted some of them before they were completed, which means that they were not employing their time efficiently.

The present results, although modest, have theoretical implications, as the findings provide empirical support for the revised theories regarding self-regulation and goal orientation. Consistent with the theoretical descriptions, mastery-oriented students manage their time in a more efficient way than do performance-oriented students. We expect this work to be the starting point for future studies using objective measures in research on self-regulated learning. We encourage researchers to employ objective tests in their studies to replicate previous results obtained with subjective measures, as well as to expand our knowledge about self-regulated learning.

In addition, the present results have potential implications in the educational field, at least at the university level. In a context in which tasks of different values are to be completed, educators should take into account the goal orientations of their students. Moreover, as performance-oriented students tend to manage their time less effectively, they might benefit most from time management training programs. For 
intervention programs, we can draw the following recommendations. As derived from research, it may be beneficial, in the first instance, to promote mastery-orientation in the classroom. This type of orientation favors higher levels of learning, which results in a better predisposition to learn how to manage time. To promote a learning orientation, educators should give greater importance to the process than to the result of completing a task, in addition to emphasizing effort and a thorough understanding of task requirements (e.g., Ames, 1992; Digelidis et al., 2003; Leondari \& Gialamas, 2002; Maehr, 1991; Sosik et al., 2017). On the other hand, it will be appropriate for educators to make available tasks of different values and deadlines so that students have the opportunity to learn to manage their time better. Students who intend to self-regulate their behavior should be aware that trying to learn the process can be very beneficial in the medium and long term and that, when faced with different tasks, they should first complete those with higher values. Between two activities of the same value, students should first complete the one that has a nearer deadline (e.g., Basila, 2014; Claessens et al., 2007; Koch \& Kleinmann, 2002, 2006).

Both educators and researchers can employ objective measures to determine students' goal orientations and their scores on time management. We expect that the results of our studies might promote future experimental studies in which intervention programs are applied to determine their effect on students' time management. We would like to point out some of the main limitations of our study. Our sample was made up of psychology students, and therefore, the generalization of the results is limited. Future works should obtain data on samples made up of participants of different educational levels and professional environments. Besides, this work is not experimental, so this prevents us from establishing causal relations among the manipulated variables. On the other hand, a limitation of the data analysis is that we conducted multiple $t$-test, which increase the change of type I errors (familywise errors; see Perneger, 1998). Nevertheless, as mentioned, the present study is intended to establish a precedent for future research. We believe that this work is a starting point and that future studies should be able to replicate and extend these results.

In short, our study shows that mastery-oriented students manage their time more efficiently, and this has been found based on objective behavioral measures. The results contribute to expanding the conceptual analysis of goal orientation and time management, and justify their joint consideration from the perspective of self-regulated learning models. Behavioral data on goal orientation and time management obtained in our study complement previous works that have mainly employed selfreports. Objective tests provide information about the participant's behavior that is not affected by any bias or inaccuracy in participants' responses. Therefore, they are useful instruments that have the potential to expand our knowledge about goal orientation and time management and the relations among these and other self-regulated learning constructs.

Author Contribution Miriam Romero: conception or design, collection of data, analysis and interpretation of data, revising intellectual content.

James F. Juola: revising intellectual content.

Cristina Casadevante: collection of data, revising intellectual content.

José Manuel Hernández: revising intellectual content. 
José Santacreu: conception or design, interpretation of data, revising intellectual content.

Funding Open Access funding provided thanks to the CRUE-CSIC agreement with Springer Nature.

Availability of Data and Material The dataset analyzed during the current study is available from the corresponding author.

\section{Declarations}

Ethics Approval The study was approved by a research ethics committee. All procedures performed in studies involving human participants were in accordance with the ethical standards of the institutional and national research committee and with the 1964 Helsinki Declaration and its later amendments or comparable ethical standards.

Consent to Participate Informed consent was obtained from all individual participants included in the study.

Conflict of Interest The authors declare no competing interests.

Open Access This article is licensed under a Creative Commons Attribution 4.0 International License, which permits use, sharing, adaptation, distribution and reproduction in any medium or format, as long as you give appropriate credit to the original author(s) and the source, provide a link to the Creative Commons licence, and indicate if changes were made. The images or other third party material in this article are included in the article's Creative Commons licence, unless indicated otherwise in a credit line to the material. If material is not included in the article's Creative Commons licence and your intended use is not permitted by statutory regulation or exceeds the permitted use, you will need to obtain permission directly from the copyright holder. To view a copy of this licence, visit http://creativecommons.org/licen ses/by/4.0\%.

\section{References}

Ahmad-Uzir, N., Gašević, D., Matcha, W., Jovanović, J., \& Pardo, A. (2019). Analytics of time management strategies in a flipped classroom. Journal of Computer Assisted Learning, 36, 70-88. https:// doi.org/10.1111/jcal.12392.

Ames, C. (1992). Classrooms: Goals, structures, and student motivation. Journal of Educational Psychology, 84(3), 261-271. https://doi.org/10.1037/0022-0663.84.3.261.

Basila, C. (2014). Good time management and motivation level predict student academic success in college on-line courses. International Journal of Cyber Behavior, Psychology and Learning, 4(3), 45-52. https://doi.org/10.4018/ijcbpl.2014070104.

Bernacki, M. L., Byrnes, J. P., \& Cromley, J. G. (2012). The effects of achievement goals and self-regulated learning behaviors on reading comprehension in technology-enhanced learning environments. Contemporary Educational Psychology, 37(2), 148-161. https://doi.org/10.1016/j.cedpsych.2011. 12.001.

Britton, B. K., \& Tesser, A. (1991). Effects of time-management practices on college grades. Journal of Educational Psychology, 83(3), 405-410. https://doi.org/10.1037/0022-0663.83.3.405.

Button, S. B., Mathieu, J. E., \& Zajac, D. M. (1996). Goal orientation in organizational research: A conceptual and empirical foundation. Organizational Behavior and Human Decision Processes, 67(1), 26-48. https://doi.org/10.1006/obhd.1996.0063.

Cattell, R. B. (1958). What is" objective" in objective personality tests?. Journal of Counseling Psychology, 5(4), 285-289. https://doi.org/10.1037/h0046268.

Cattell, R. B., \& Warburton, F. W. (1967). Objective personality and motivation tests: A theoretical introduction and practical compendium. University of Illinois Press. 
Claessens, B. J. (2004). Perceived control of time: Time management and personal effectiveness at work. [Doctoral Dissertation, Universiteit Eindhoven]. TU/e. https://doi.org/10.6100/IR582438.

Claessens, B. J., Van Eerde, W., Rutte, C. G., \& Roe, R. A. (2007). A review of the time management literature. Personnel Review, 36(2), 255-276. https://doi.org/10.1108/00483480710726136.

Chu, S. T. L., Jamieson, D. L., Winne, P. H., \& Field, D. (1998). PrepMate: Studying tracker [computer program]. Simon Fraser University.

Cohen, J. (1988). Statistical power analysis for the behavioral sciences. Second Edition. LEA.

Digelidis, N., Papaioannou, A., Laparidis, K., \& Christodoulidis, T. (2003). A one-year intervention in 7th grade physical education classes aiming to change motivational climate and attitudes towards exercise. Psychology of Sport and Exercise, 4(3), 195-210. https://doi.org/10.1016/S1469-0292(02) 00002-X.

Dweck, C. S., \& Leggett, E. L. (1988). A social-cognitive approach to motivation and personality. Psychological Review, 95(2), 256-273. https://doi.org/10.1037/0033-295X.95.2.256.

Edwards, A. L. (1957). The social desirability variable in personality assessment and research. Dryden Press.

Elliot, A. J. (2005). A conceptual history of the achievement goal construct. In A. J. Elliot \& C. S. Dweck (Eds.), Handbook of Competence and Motivation (pp. 52-72). Guilford Publications.

Elliot, A. J., \& Murayama, K. (2008). On the measurement of achievement goals: Critique, illustration, and application. Journal of Educational Psychology, 100(3), 613-628. https://doi.org/10.1037/ 0022-0663.100.3.613.

Faul, F., Erdfelder, E., Buchner, A., \& Lang, A. G. (2009). Statistical power analyses using G* Power 3.1: Tests for correlation and regression analyses. Behavior Research Methods, 41(4), 1149-1160. https://doi.org/10.3758/BRM.41.4.1149.

Gonida, E. N., Voulala, K., \& Kiosseoglou, G. (2009). Students' achievement goal orientations and their behavioral and emotional engagement: Co-examining the role of perceived school goal structures and parent goals during adolescence. Learning and Individual Differences, 19(1), 53-60. https://doi. org/10.1016/j.lindif.2008.04.002.

Koch, C. J., \& Kleinmann, M. (2002). A stitch in time saves nine: Behavioural decision-making explanations for time management problems. European Journal of Work and Organizational Psychology, 11(2), 199-217. https://doi.org/10.1080/13594320244000120.

König, C. J., \& Kleinmann, M. (2006). Individual differences in the use of timemanagement mechanics and in time discounting. Individual Differences Research, 4(3), 194-207. https://doi.org/10.3200/ JRLP.139.1.33-45.

König, C. J., \& Kleinmann, M. (2007). Time management problems and discounted utility. The Journal of Psychology, 141(3), 321-334. https://doi.org/10.3200/JRLP.141.3.321-336.

Leondari, A., \& Gialamas, V. (2002). Implicit theories, goal orientations, and perceived competence: Impact on students' achievement behavior. Psychology in the Schools, 39(3), 279-291. https://doi. org/10.1002/pits.10035.

Luo, W., Paris, S. G., Hogan, D., \& Luo, Z. (2011). Do performance goals promote learning? A pattern analysis of Singapore students' achievement goals. Contemporary Educational Psychology, 36(2), 165-176. https://doi.org/10.1016/j.cedpsych.2011.02.003.

Macan, T. H., Shahani, C., Dipboye, R. L., \& Phillips, A. P. (1990). College students' time management: Correlations with academic performance and stress. Journal of Educational Psychology, 82(4), 760-768. https://doi.org/10.1037/0022-0663.82.4.760.

Maehr, M. L. (1991). The "psychological environment" of the school: A focus for school leadership. In P. Thurston \& P. Zodhiates (Eds.), Advances in educational administration (pp. 51-81). JAI Press Inc.

Magno, C. (2012). Assessing students' study strategies and achievement goals. The International Journal of Educational and Psychological Assessment, 12(1), 108-131. https://bit.ly/33rbG5g.

Midgley, C., Maehr, M. L., Hruda, L. Z., Anderman, E., Anderman, L., Freeman, K. E., Gheen, M., Kaplan, A., Kumar, R., Middleton, M. J., Nelson, J., Roeser, R., \& Urdan, T. (2000). Manual for the patterns of adaptive learning scales (PALS). University of Michigan. https://bit.ly/2X7O6t9.

Morrone, A. S., \& Schutz, P. A. (2000). Promoting achievement motivation. In K. M. Minke \& G. C. Bear (Eds), Preventing school problems-promoting school success: strategies and programs that work (pp. 143-169). National Association of School Psychologists.

Núñez, J. C., Solano, P., González-Pienda, J. A., \& Rosário, P. (2006). Evaluación de los procesos de autorregulación mediante autoinforme. [Assessing self-regulation proccesses through a self-report]. Psicothema, 18(3), 353-358. https://bit.ly/3c2btZl. 
Ortner, T. M., \& Proyer, R. T. (2015). Objective personality tests. In T. M. Ortner \& F. J. R. Van de Vijver (Eds.), Behavior-Based Assessment in Psychology (pp. 133-149). Hogrefe.

Panadero, E. (2017). A review of self-regulated learning: Six models and four directions for research. Frontiers in Psychology, 8, 422. https://doi.org/10.3389/fpsyg.2017.00422.

Payne, S. C., Youngcourt, S. S., \& Beaubien, J. M. (2007). A meta-analytic examination of the goal orientation nomological net. Journal of Applied Psychology, 92(1), 128-150. https://doi.org/10.1037/ 0021-9010.92.

Perneger, T. V. (1998). What's Wrong with Bonferroni Adjustments. BMJ (clinical Research Ed.), 316(7139), 1236-1238. https://doi.org/10.1136/bmj.316.7139.1236.

Petersen, A., Craig, M., Campbell, J., \& Tafliovich, A. (2016). Revisiting why students drop CS1. Proceedings of the 16th Koli Calling International Conference on Computing Education Research Koli Calling, 16, 71-80. https://doi.org/10.1145/2999541.2999552.

Pike, G. R. (1995). The relationship between self reports of college experiences and achievement test scores. Research in Higher Education, 36, 1-21. https://bit.ly/348HbBq.

Pintrich, P. R. (2000). The role of goal orientation in self-regulated learning. In M. Boekaerts, P. R. Pintrich, \& M. Zeidner (Eds.), Handbook of Self-Regulation: Theory, Research, and Applications (pp. 451-502). Academic Press.

Ranellucci, J., Hall, N. C., \& Goetz, T. (2015). Achievement goals, emotions, learning, and performance: A process model. Motivation Science, 1(2), 98-120. https://doi.org/10.1037/mot0000014.

Romero, M., Hernández, J. M., Juola, J. F., Casadevante, C., \& Santacreu, J. (2020). Goal orientation test: An objective behavioral test. Psychological Reports, 123(4), 1425-1451. https://doi.org/10.1177/ 0033294119845847.

Romero, M., Hernández, J. M., Juola, J. F., Casadevante, C., \& Santacreu, J. (2021). A complementary methodology to assess time management behaviors. Current Psychology. https://doi.org/10.1007/ s12144-021-01578-X.

Santacreu, J. (2004). Planning Test. Registration number, R.P.O.: M-003406.

Santacreu, J., \& Hernández, J. M. (2017). T-data (Tests). In V. Zeigler-Hill and T. K. Shackelford (Eds.), Encyclopedia of Personality and Individual Differences (pp.1-4). Springer.

Santacreu, J., Rubio, V. J., \& Hernández, J. M. (2006). The objective assessment of personality: Cattell's T-data revisited and more. Psychology Science, 48(1), 53-68. https://goo.g1/2sT11W.

Scheier, I. H. (1958). What is an "objective" test? Psychological Reports, 4(1), 147-157. https://doi.org/ 10.2466/pr0.1958.4.g.147.

Sevary, K., \& Kandy, M. (2011). Time management skills impact on self-efficacy and academic performance. Journal of American Science, 7(12), 720-726. https://bit.ly/2Ibi0UO.

Sosik, J. J., Chun, J. U., \& Koul, R. (2017). Relationships between psychological wellbeing of Thai college students, goal orientations, and gender. Psychology in the Schools, 54(7), 703-717. https://doi. org/10.1002/pits.22024.

Thibodeaux, J., Deutsch, A., Kitsantas, A., \& Winsler, A. (2017). First-year college students' time use. Journal of Advanced Academics, 28(1), 5-27. https://doi.org/10.1177/1932202X16676860.

Winne, P. H., \& Jamieson-Noel, D. (2002). Exploring students' calibration of self-reports about study tactics and achievement. Contemporary Educational Psychology, 27(4), 551-572. https://doi.org/10. 1016/S0361-476X(02)00006-1.

Winne, P. H., Nesbit, J. C., Kumar, V., Hadwin, A. F., Lajoie, S. P., Azevedo, R., \& Perry, N. E. (2006). Supporting self-regulated learning with gStudy software: The Learning Kit Project. Technology Instruction Cognition and Learning, 3(1/2), 105-113. https://go.aws/2V6jzKR.

Won, S., Wolters, C. A., \& Mueller, S. A. (2018). Sense of belonging and self-regulated learning: Testing achievement goals as mediators. The Journal of Experimental Education, 86(3), 402-418. https:// doi.org/10.1080/00220973.2016.1277337.

Zimmerman, B. J. (1996). Enhancing student academic and health functioning: A self-regulatory perspective. School Psychology Quarterly, 11(1), 47-66. https://doi.org/10.1037/h0088920.

Zimmerman, B. J. (2000). Attaining self-regulation: A social cognitive perspective. In M. Boekaerts, P. R. Pintrich y M. Zeidner (Eds.), Handbook of Self-Regulation (pp. 13-40). Academic Press.

Zimmerman, B. J. (2008). Investigating self-regulation and motivation: Historical background, methodological developments, and future prospects. American Educational Research Journal, 45(1), 166183. https://doi.org/10.3102/0002831207312909.

Zimmerman, B. J. (2013). From cognitive modeling to self-regulation: A social cognitive career path. Educational Psychologist, 48(3), 135-147. https://doi.org/10.1080/00461520.2013.794676. 